\title{
RESENHAS
}

REVIEWS

CAPPelen, Herman. Fixing Language: An Essay on Conceptual Engineering. Oxford: Oxford University Press, 2018.

SAmuel MaIA. Universidade Federal de Minas gerais, BRAsil

samuelmaia@ufmg.br

RECEIVED: $13 / 11 / 2020$

ACCEPTED: $16 / 08 / 2021$

Fixing Language (2018) é mais uma contribuição de Herman Cappelen à metafilosofia (2012; 2013; cf. também Cappelen, Gendler e Hawthorne 2016). Neste livro, Cappelen pretende oferecer motivos para considerarmos a engenharia conceitual (EC) uma atividade filosófica unificada e frutífera o suficiente para ser considerada uma das, se não a principal, questão em filosofia (2018, p.i). A EC consiste no processo de avaliação e aperfeiçoamento de nossos instrumentos representacionais (2018, p.1). Engenheiros conceituais não querem descrever ou analisar esses instrumentos, isto é, não buscam identificar o conteúdo dos conceitos que já possuímos, mas, sim, avaliar se cumprem aquilo que achamos que deveriam expressar ou representar.

Há muitos que rejeitam essa forma de conceber a atividade filosófica. Dizem, ao contrário, que a filosofia é primariamente uma atividade descritiva (Strawson 1959, p.9; 1963). Ainda assim, para Cappelen, exercícios de EC poderiam ser encontrados em toda parte, na filosofia e além. Em epistemologia e filosofia da mente, há quem defenda mudanças nos conceitos de crença e conhecimento. Em metafísica, mudanças nos conceitos de verdade e liberdade. Em filosofia das ciências, naturais ou sociais, mudanças nos conceitos de espécie, gênero e raça. Para além da filosofia, no direito há debates sobre o significado de pessoa e estupro; na psiquiatria, discussões sobre as definições que figurarão no novo DSM; em parlamentos, legisladores discutem o que é casamento ou quem conta como refugiado - todos estão, para Cappelen, fazendo EC.

Contudo, neste livro Cappelen não propõe a revisão de um conceito específico. Sua ambição é mais ampla: (i) defender que esses diferentes projetos são todos exemplos de uma mesma atividade, a EC, e (ii) oferecer uma teoria geral dessa atividade, chamada de Quadro Austero ["Austerity Framework"], na qual fornece uma descrição e desenvolvimento de pontos e desafios gerais a toda instância de EC.

Esta resenha está dividida em duas partes. Na primeira, apresento uma visão geral do livro. Na segunda, discuto em detalhes dois pontos da teoria geral de Cappelen 
para a EC: a continuidade de assunto e a falta de controle. Mas antes de prosseguirmos, dois avisos. A expressão "engenharia conceitual" é um termo impróprio, pois para Cappelen a EC não diz respeito a conceitos e, na maior parte das vezes, nem mesmo é capaz de realizar seus projetos de melhoria ou revisão. Isso ficará claro mais adiante. Contudo, ele acredita que vale preservar esse rótulo pois captura a autoimagem de muitos praticantes da EC e encoraja o desenvolvimento de quadros teóricos alternativos ao dele (2018, pp.199-200). Além disso, dadas as limitações de espaço e a variedade de questões tratadas (em apenas duzentas páginas!) no livro, deixarei de lado muitos pontos interessantes, os quais recomendo que a leitora e leitor confiram diretamente.

\section{Uma visão geral}

Fixing Language é dividido em cinco partes. Na parte I, Cappelen apresenta: exemplos de EC em filosofia e fora dela (Cap. 2); argumentos em favor da relevância da EC (Cap. 3); e argumentos em favor de uma teoria geral sobre sua prática (Cap. 4). Para quem deseja se familiarizar com o assunto, a leitura dessa parte é por si só altamente recomendável. Especialmente o segundo capítulo, cuja última seção apresenta uma taxonomia da EC.

As três partes seguintes são dedicadas à teoria geral da EC. Na parte II, somos apresentados aos pressupostos metassemânticos (isto é, aos fundamentos de todos os fatos semânticos particulares) externistas da teoria de Cappelen (Cap.5 e Cap.6). Sua teoria pressupõe uma metassemântica na qual o que muda com a EC não são conceitos, mas somente os valores semânticos de expressões - aqui, estamos falando de mudanças nas extensões de expressões, especificamente, naquelas mudanças causadas por mudanças nas intensões (2018, pp.61-2). Sua teoria é externista pois assume que o ambiente externo, natural e social, determina as extensões das expressões dos falantes (Putnam 1975; Burge 1979). Este último aspecto, em especial, tem duas consequências: considera-se que a referência dos termos é suficientemente estável ao longo do tempo e ao longo de diferentes falantes; mas a referência também pode mudar na medida em que a própria base do significado dos termos pode mudar (Evans 1973, pp.199-202; Kripke 1980, p.163). O problema é que, como os significados são determinados por fatores externos, e como os processos por trás de cada mudança de significado são muito complexos e amorfos, reformá-los intencionalmente na maior parte das vezes resulta em fracasso e, quando ocorre, o resultado das reformas é imprevisível. Cappelen chama esses dois aspectos de, respectivamente, falta de controle e inescrutabilidade da EC (Cap.7). Naturalmente, isso nos faz perguntar se a EC não seria um despropósito: qual o sentido de se engajar numa atividade cujo objetivo está tão fora de nosso alcance e compreensão? Ao final da resenha falarei mais sobre isso. Esta parte termina com críticas à noção de conceitos inconsistentes (Cap.8). 
Na parte III (Caps.9, 10 e 11), somos apresentados a uma objeção à EC e duas possíveis respostas. Essa objeção teria sido levantada pela primeira vez por Strawson (1963) em crítica às explanações de Carnap e, além do próprio Cappelen, preocuparia outras praticantes da EC (e.g., Haslanger 2000, p.34): é o problema da continuidade de assunto. Segundo a objeção, como mudanças em extensões de expressões implicam em mudanças sobre aquilo que estamos falando, quando projetos revisionários são bem-sucedidos, simplesmente mudamos de assunto (2018, p.100).

Suponha o seguinte: Estamos interessados no termo "mulher", especificamente, interessados em perguntas como "O que é ser uma mulher?" ou "Por que mulheres recebem menos do que homens?". Agora, suponha que conseguimos revisar o termo "mulher", mudando seu significado de "indivíduo com tais órgãos reprodutores" para "indivíduo que ocupa posição subordinada na hierarquia social em virtude de supostas características biológicas" (Haslanger 2000). Assim, a extensão desse termo muda de $F$ para $G$. Posteriormente, tentamos responder às questões que formulamos prérevisão usando o mesmo termo, "mulher", mas com a nova extensão. Agora, as questões pós-revisão dizem respeito a coisas distintas $(G)$ daquelas que eram objeto das questões pré-revisão $(F)$. Em outras palavras, não estamos respondendo às questões antigas, mas a novas questões (2018, p.102).

Cappelen apresenta duas respostas possíveis a esse problema. Uma delas seria simplesmente ignorá-lo e explorar os chamados "efeitos lexicais" (Cap.11). Estes seriam os efeitos cognitivos e emocionais que itens lexicais provocam nos ouvintes, independentemente de seus valores semânticos. Por exemplo, parece que uma palavra como "democrático" costuma provocar e é associada a atitudes positivas nas pessoas. Essas atitudes podem permanecer mesmo que as extensões ou intensões do termo mudem. Assim, suponha que um engenheiro conceitual, interessado em promover uma política $X$, proponha uma revisão na intensão do predicado "democrático", de modo que tendo a revisão sido bem-sucedida, essa política $X$, antes tida como não democrática, passe a ser assim considerada pelos falantes de uma comunidade. Nesse caso, não importa se, após a revisão, estamos ou não mudando de assunto. O que importa é que, agora, as atitudes positivas associadas a "democrático" são estendidas à política $\mathrm{X}$, mesmo que os falantes não estejam conscientes da possível mudança sofrida nos valores semânticos desse predicado. Isso pode ser benéfico para os fins políticos desse engenheiro conceitual.

Cappelen concorda que a filosofia da linguagem deveria investigar melhor os efeitos lexicais, mas os rejeita como uma alternativa ao problema pois explorá-los dessa maneira significa explorar a confusão comunicacional, minar a comunicação genuína e o discurso racional. Ao contrário, a resposta que ele propõe ao problema da continuidade é defender que revisões são compatíveis com a manutenção dos assuntos, pois assuntos são menos granulares do que valores semânticos, isto é, o valor semântico das expressões pode mudar sem que o assunto mude (Cap.10). Se 
aceitarmos que isso acontece e é justificado, é possível que falemos sobre o mesmo assunto, ainda que as expressões em jogo envolvam extensões diferentes. Assim a continuidade do assunto seria compatível com a revisão. Também falaremos mais sobre isso abaixo.

Na parte IV, Cappelen conclui seu argumento em defesa da teoria geral apresentando três candidatos a objetos da EC: conceitos; palavras e seus significados; o mundo (Cap.12). A primeira opção é rejeitada pois, em filosofia e psicologia dos conceitos, há muitas respostas à pergunta o que conceitos são (e.g., objetos platônicos ou sentidos fregianos, protótipos, exemplares ou teorias), mas pouco consenso (Machery 2009). Por isso, rejeitar que a EC trate de conceitos é não comprometer sua teoria com um debate tão controverso. Sabemos que Capellen aceita a segunda opção, afinal, o objeto da EC são instrumentos representacionais (as palavras e suas extensões).

Mas para além disso, revisões também podem ser sobre o próprio mundo, isto é, aquilo sobre os quais as palavras se referem. Nesse sentido, Cappelen fala na mundanidade ["Worldliness"] da EC. Em defesa dessa tese, Cappelen se vale de outra distinção conhecida de seus trabalhos anteriores (Cappelen e Lepore 2005), aquela entre conteúdo semântico e conteúdo de atos de fala. Não somente assuntos, mas aquilo que dizemos, nossos atos de fala, são menos granulares, quer dizer, vão além daquilo que é semanticamente expresso. Por isso, é possível que aquilo que expressamos seja verdadeiro, ainda que a proposição semanticamente expressa seja falsa (2018, pp.138-9). Assim também é possível que, mesmo depois da mudança dos valores semânticos de uma expressão - e.g., "família" - ainda estejamos falando sobre o mesmo assunto - isto é, família simpliciter, sem aspas. Nos capítulos restantes dessa parte (Caps.13 e 14), Cappelen detalha um pouco mais sua teoria geral, assim como a defende de algumas das principais objeções contra ela levantadas.

Finalmente, na parte $\mathrm{V}$ são apresentadas e rejeitadas concepções alternativas aos objetos da EC. Essas alternativas se baseiam em: negociações metalinguísticas (Cap. 15); apelos ao propósito ou função dos conceitos (Cap.16); a defesa de subscritos como formas de evitar disputas verbais (Cap.17); a existência de conceitos básicos (Cap. 18).

Agora, falemos detidamente de duas teses da teoria geral da EC de Cappelen: a continuidade do assunto e a falta de controle.

\section{Discussão e crítica}

\subsection{A continuidade de assunto}

$\mathrm{O}$ argumento de Cappelen em favor da compatibilidade de revisões linguísticas com a continuidade de assunto é o seguinte. Se é possível dizer a mesma coisa ainda que 
haja mudanças de extensão, é possível haver continuidade de assunto mesmo que tenham ocorrido revisões linguísticas que envolvem mudanças de extensão. Assim, para seu argumento funcionar, Cappelen precisa apresentar evidências linguísticas robustas o suficiente em favor desse dizer a mesma coisa.

Cappelen diz que frequentemente encontramos situações deste tipo: $A$ e $B$ dizem " $F a$ " em contextos e tempos diferentes; a extensão de $F$ é contexto e temporalmente dependente; por isso, a extensão de $F$ na enunciação de $A$ é diferente da extensão de $F$ na enunciação de $B$; mas, mesmo assim, tomamos como verdadeiro relatos como " $A$ e $B$ disseram que $F a$ ".

Quais exemplos desse tipo de situação Cappelen oferece? Sobre casos de dependência contextual, os dados se resumem a apenas um: $A$ e $B$ enunciam, em contextos diferentes, a frase "Serena é muito esperta" [Serena is really smart]. Como "esperta" é um predicado contextualmente dependente, e os contextos e pressupostos de fundo de $A$ e de $B$ são diferentes, as extensões e intensões de "esperta" na enunciação de $A$ e de $B$ são diferentes. Ainda assim, afirma Cappelen, consideramos verdadeiros relatos como " $A$ e $B$ disseram que Serena é esperta", ou " $A$ e $B$ concordam que Serena é esperta", ou " $A$ e $B$ disseram a mesma coisa sobre Serena" (2018, p.110). Sobre dizer o mesmo em tempos diferentes, Cappelen se vale das considerações de Dorr e Hawthorne (2014) sobre a evolução da extensão de "salada" que, mesmo sendo temporalmente dependente, frequentemente relatamos que discursos sobre salada feitos em tempos diferentes dizem a mesma coisa (2018, pp.111-2).

Apesar da centralidade do problema da continuidade do assunto para a teoria geral de Cappelen (2018, pp.105-6), essas evidências são esparsas, e sua análise não é convincente, pois ignora outras interpretações desses mesmos relatos, mas contrárias à tese do dizer o mesmo. Conforme Koch (2019), é possível que esses relatos: não sejam justificados; não sejam instâncias de dizer o mesmo, mas enunciações suficientemente similares dados os propósitos comunicativos no qual ocorrem; sejam restritos a termos especiais, como "salada". Todas essas são intepretações compatíveis com os mesmos dados linguísticos. Por isso, Cappelen nos deve outras razões para considerarmos a sua interpretação como sendo a superior. Enquanto isso, a continuidade do assunto continua sendo um problema não resolvido por sua teoria.

\subsection{O problema da "falta de controle"}

Propostas de revisão dos valores semânticos das expressões feitas por engenheiros conceituais parecem supor que convencendo as pessoas sobre aquilo que as palavras devem significar, mudam-se o significado das palavras. Para Cappelen, isso é uma ilusão. Vejamos por quê.

Cappelen divide a metassemântica entre base e superestrutura (2018, pp.58-9). A superestrutura diz respeito às nossas crenças, esperanças, preferências, intenções 
e outras atitudes sobre significado e referência, isto é, àquilo que achamos que esses fatos semânticos são e o que queremos que eles sejam. A base diz respeito aos fatos que determinam os fatos semânticos, isto é, o significado e a referência de expressões.

Interessa aos engenheiros conceituais saber o seguinte: a superestrutura metassemântica afeta a base metassemântica, e, se sim, como? Quanta discrepância pode haver entre a superestrutura e um determinado fato semântico (que é determinado pela base)? Dados os compromissos externistas de Cappelen, sua teoria assume que valores semânticos são afetados, para além dos estados mentais dos falantes, por várias coisas, especialmente coisas do passado, como eventos introdutórios de batismo, correntes de comunicação, juízos de e deferências a especialistas, o ambiente dos falantes etc. O problema para a EC seria que os efeitos dos estados mentais na base são muito pequenos e imprevisíveis (2018, p.60, p.66, p.73). Além disso, ainda que diferentes teorias externistas assumam que valores semânticos mudem, nenhuma delas oferece os detalhes dessas mudanças. Para piorar, Cappelen defende que não somente a semântica, mas a própria metassemântica dos termos pode mudar. Ou seja, podem mudar os significados dos termos e as condições e regras segundo as quais essas mudanças ocorrem (2018, pp.69-70). Por isso: "apresentar um argumento em favor da mudança de um conceito particular afeta mudanças conceituais não mais do que apresentar um argumento sobre como diminuir o crime em Baltimore afeta o crime em Baltimore. Ambos não têm efeito algum" (2018, p.60).

O problema é que se Cappelen estiver certo, a EC é um exercício frívolo: seu impacto não corresponderá às altas expectativas de suas praticantes. Estas, aliás, costumam ter, para além de preocupações semânticas, expectativas de que suas revisões contribuam para diferentes projetos políticos e morais (e.g., Haslanger 2000, 2006; Saul 2006). A isso Cappelen responde duas coisas. Primeiro sugere que, apesar desses limites, dadas as nossas disposições psicológicas é provável (e desejável) que continuemos engajados na EC (2018, p.73). Segundo, não somente a EC, mas todo projeto com pretensões normativas amplas demais (tais como teorias ideais da justiça) sofre do mesmo problema. Ainda assim, todos esses empreendimentos nos ofereceriam coisas valiosas: isto é, aquilo que deve ser o caso, ainda que não nos digam como implementar aquilo que deve ser o caso (2018, pp.83-4, pp.200-1).

Dito isso, tenho dois pontos a fazer sobre a tese da falta de controle e suas implicações para a EC:

- Ponto 1. Uma investigação adequada do objeto da tese da falta de controle - isto é, a relação entre superestrutura e base metassemânticas — precisa recorrer às ciências, especialmente às ciências sociais. Contudo, a defesa de Cappelen é feita somente a partir de argumentos filosóficos tradicionais.

- Ponto 2. Há um sentido no qual a verdade ou falsidade da tese da falta de controle não importa para muitos daqueles engenheiros conceituais que, com suas propos- 
tas de revisão, ambicionam contribuir para a realização de determinado objetivo político ou moral: Muitos avanços em prol desses objetivos não necessitam de revisões semânticas globais, mas somente de revisão e melhoria da linguagem em contextos bem mais restritos - especialmente contextos científicos e institucionais.

Falemos primeiro do ponto 1. Em sua defesa da falta de controle, Cappelen afirma que não temos acesso às informações sobre todos os fatos passados que determinam a intensão de termos como "pessoa" ou "casamento", nem a informações sobre mecanismos de mudança de referência que podem, inclusive, ser por demais complexos (2018, p.74). Além disso, mesmo se tivéssemos acesso a essas informações e fôssemos grupos perfeitamente coordenados em nossas ações e intenções sobre a referência desses termos, não controlaríamos a fixação de sua referência, pois os efeitos de ações e intenções teria, na melhor das hipóteses, um efeito imprevisível nesses valores semânticos.

Em dado momento, Cappelen diz

[t]alvez a mudança social em geral [também] aconteça assim: o que queremos, dizemos, esperamos etc. cumpre importante papel de afetar mudanças de larga escala em estruturas sociais, mas esse papel não se adequa ao que queremos, dizemos, esperamos etc. (2018, p.74).

A EC também é chamada de "um tipo de mudança social no campo do significado" (2018, p.78). Bom, se isso é assim, as disciplinas que estudam processos de mudança social têm importante papel a cumprir nessa investigação. Qualquer estudo do tópico que não recorresse aos estudos empíricos, a partir das ciências sociais, acerca da população, mecanismos e efeitos em questão ofereceria no máximo conjecturas a serem investigadas. Afinal, é isso o que acontece no estudo de outros objetos dessas ciências. Por exemplo, determinar os efeitos de diferentes arranjos coordenativos para a produção de determinados objetos, tais como renda, emprego e resultados eleitorais, é um dos objetivos da economia, ciência política e sociologia, que por sua vez possuem diversos métodos para investigar esses efeitos. Claro, há muitas disputas acerca da adequação e validade de cada um desses métodos. Mas não se presume que quaisquer dessas questões sejam resolvidas somente a partir de argumentos que partem de nossas observações linguísticas ordinárias, por mais sofisticadas que sejam essas observações.

Para usar o exemplo de Cappelen (2018, pp.76-7), se queremos saber se os efeitos, em cortes inferiores e na prática jurídica em geral, de uma decisão da Suprema Corte dos EUA - que, e.g., determina que o termo "pessoa" também captura aquelas coisas capturadas pelo termo "corporações" - são aqueles efeitos esperados pelos membros dessa corte, ou mesmo se são aqueles efeitos ditados pelo direito, precisamos olhar para outras decisões jurídicas, trabalhos doutrinários e para a opinião de 
especialistas. Pode ser o caso que esses efeitos sejam bastante diferentes daqueles previstos pelos membros da Suprema Corte, ou mesmo daqueles previstos pela própria lei. Mas isso só saberemos olhando para as evidências relevantes, o que certamente não podemos fazer sem consultar disciplinas como filosofia do direito e sociologia do direito.

Este ponto é, aliás, o mesmo da crítica de Saul (2006) ao projeto de revisão do significado de termos como "mulher" proposto por Haslanger (2006). Primeiro, Saul argumenta que esse tipo de revisão pode oferecer mais riscos de confusão comunicativa (especialmente entre feministas e usuários comuns da linguagem) do que vantagens para defensoras de pautas feministas. Mas ao fim e ao cabo, Saul concorda que riscos ou eventuais benefícios de revisões são questões empíricas, de modo que a avaliação da eficácia de propostas revisionárias como a de Haslanger escapam do alcance da filosofia (Saul 2006, pp.138-9, p.142).

Cappelen poderia responder que, ainda que tudo isso seja interessante de um ponto de vista jurídico, econômico ou sociológico, não serviria de motivo para abandonarmos sua tese metassemântica de que a referência desses termos não muda, no caso da decisão da Suprema Corte, com uma canetada judicial. Afinal, ao tomar ao decidir sobre o termo "pessoa", esse tribunal não muda seu significado, mas sim força "certas pessoas a interpretar erroneamente frases contendo "pessoas" de uma maneira particular", a partir de certas dimensões e contextos (2018, p.76). Parece que Cappelen quer dizer que o significado desses termos (ou de qualquer outro) não é, em última análise, acessível empírica e cientificamente. As preocupações semânticas ou metassemânticas teriam, assim, um escopo global que sempre escaparia de investigações empíricas. Assim, supondo que o externismo esteja correto, para sabermos qual a extensão de um termo num dado momento e contexto, precisaríamos conhecer todos os elementos que fixam sua referência (todos os eventos introdutórios de batismo, todas as correntes de comunicação, todos os juízos de e deferências a especialistas, tudo sobre o ambiente dos falantes etc.). Em comparação, sabemos que cientistas (naturais ou sociais) constroem teorias e modelos a partir de abstrações sobre as múltiplas causas que atuam para a ocorrência de determinado fenômeno, assumindo coisas como condições iniciais e ausência de causas perturbadoras. Enfim, se as pretensões metassemânticas de Cappelen possuem escopo global, nenhuma investigação empírica parece ser capaz de dizer algo sobre elas. Sob essa interpretação, a tese da falta de controle parece ser imune às ciências.

Devo dizer que essa interpretação de Cappelen contrasta com os convites que ele mesmo faz a contribuições, de várias disciplinas, à investigação da relação entre a base e a estrutura metassemântica (2018, p.x, pp.117-8, p.193). Porém, em última análise, parece que nenhuma dessas disciplinas teria coisas interessantes a dizer sobre a tese da falta de controle: parece que nenhum estudo seria capaz de fornecer evidência contra, ou mesmo a favor dela. 
Contudo, mesmo se esse for o caso, para produzirmos os efeitos políticos e sociais que ocupam muitos engenheiros conceituais, não precisamos produzir esse tipo de impacto semântico global. Esse é o meu ponto 2. Tomemos novamente o exemplo da decisão da Suprema Corte. Ela não mudou o valor semântico de "pessoa", pois para tal teria que ter modificado, por fiat, tudo o que é metassemanticamente relevante (todas as atitudes e propriedades naturais relativas ao termo). Mas isso não importa, pois o que realmente importa é que, dado o espaço político e jurídico que essa corte ocupa na sociedade norte-americana, suas interpretações são capazes de influenciar uma comunidade especial, isto é, a dos juristas, que por sua vez influencia fortemente a vida de todos os outros norte-americanos. O impacto dessa mudança interpretativa terá forte impacto político e social, e será razoavelmente previsível, ainda que não signifique mudança na extensão de "pessoa". Terá sido, em conformidade com a tese da falta de controle, metassemanticamente fracassada. Mas ainda assim relevante. Por isso, dados alguns dos objetivos políticos, morais e sociais de muitos engenheiros conceituais, o impacto metassemântico de suas revisões não seria uma questão que merece preocupação.

Esforços de revisão especialmente promissores são aqueles direcionados a mudanças locais dos termos e expressões. Inclusive, muitos dos filósofos considerados por Cappelen importantes engenheiros conceituais realizaram seus trabalhos revisionários a partir de disciplinas científicas específicas: Por exemplo, Frege e Russell na lógica e na matemática, Carnap na física e Neurath na economia.

Nesses lugares há pelo menos dois aspectos particularmente atraentes: comunidades científicas oferecem recursos linguísticos que facilitam revisões; e o espaço social, institucional e político, ocupado pelas ciências é privilegiado. Sobre o primeiro ponto, por exemplo, frequentemente em ciências sociais termos abstratos, tais como "acesso à justiça" ou "pobreza", são definidos e operacionalizados sem preocupações semânticas globais, mas simplesmente de maneira que pesquisadores possam recolher evidência sobre eles. Podemos discordar do conteúdo dessas operacionalizações, e boa parte das discussões nessas disciplinas consiste nesse tipo de crítica. Mas por si só esse recuso oferece uma maneira de desviarmos dos problemas das ambições metassemânticas globais, o que é positivo.

Para além disso, essas discussões frequentemente ocupam cenários institucionais e governamentais, cujos efeitos são razoavelmente previsíveis e relevantes ao, por exemplo, informarem relatórios e decisões governamentais que, por sua vez, influenciam políticas e debates públicos. É isso o que acontece em discussões em economia do desenvolvimento e do bem-estar, onde foram (e ainda são) propostas diferentes definições para termos como "bem-estar", "desigualdade" e "pobreza". Essas discussões têm alvos muito claros: aquelas definições usadas pelas agências nacionais e internacionais que produzem indicadores socioeconômicos. Quem propõe ao Instituto Brasileiro de Geografia e Estatística uma nova definição para "pobreza" não 
espera mudar a extensão de "pobreza" em todo o Brasil. O que espera é modificar a maneira desse instituto mensurar esse fenômeno social, mensuração que, por sua vez, alimenta debates e políticas públicas em torno da pobreza no país. (Um exemplo ilustrativo de proposta explicitamente revisionária nesse campo é Stiglitz et al. (2009).)

Claro, não nego que haja projetos revisionários cuja pretensão é influenciar não somente especialistas ou membros de governo, mas toda uma comunidade linguística. Esse certamente é o caso de muitos projetos de EC. Ainda assim, saber se eles estão realmente fadados ao fracasso depende das investigações empíricas que quis incentivar com o ponto 1 .

Fixing Language de Herman Cappelen é uma excelente e instigante introdução às discussões em torno da engenharia conceitual. Para além de sua própria teoria sobre a EC, Cappelen diz que espera que seu livro motive a oferta de narrativas sobre essa prática diferentes da sua. Dado escopo e controvérsia de suas teses, apostaria que pelo menos aqui ele será bem-sucedido e, por isso, seu livro se constituirá numa importante contribuição à filosofia.

\section{Referências}

Burge, T. 1979. Individualism and the Mental. Midwest Studies in Philosophy 4: 73-121.

Cappelen, H. 2012. Philosophy without Intuitions. Oxford: Oxford University Press.

Cappelen, H. 2013. Nonsense and illusions of thought. Philosophical Perspectives 27(1): 2250.

Cappelen, H.; Lepore, E. 2005. Insensitive Semantics: A Defense of Semantic Minimalism and Speech Act Pluralism. Oxford: Blackwell.

Cappelen, H.; Gendler, T. S.; Hawthorne, J. (eds.) 2016. The Oxford handbook of philosophical methodology. Oxford: Oxford University Press.

Dorr, C.; Hawthorne, J. 2014. Semantic Plasticity and Speech Reports. Philosophical Review 123(3): 281-338.

Evans, G. 1973. The causal theory of names. Aristotelian Society Supplementary Volume 47(1): 187-208.

Haslanger, S. 2000. Gender and Race: (What) are They? (What) Do We Want Them To Be? Noûs 34: 31-55.

Haslanger, S. 2006. What Good are Our Intuitions? Proceedings of the Aristotelian Society: Supplementary Volume 80: 89-118.

Kripke, S. 1980. Naming and Necessity. Cambridge-MA: Harvard University Press.

Koch, S. 2019. Review of Herman Cappelen, Fixing Language: an essay on conceptual engineering. Logical Analysis and History of Philosophy 22(1): 248-56.

Machery, E. 2009. Doing Without Concepts. Oxford: Oxford University Press. 
Putnam, H. 1975. The meaning of 'meaning'. Minnesota Studies in the Philosophy of Science 7: 131-93.

Saul, J. 2006. Gender and Race. Proceedings of the Aristotelian Society: Supplementary Volume 80: 119-43.

Stiglitz, J.; Sen, A.; Fitoussi, J.-P. 2009. The measurement of economic performance and social progress revisited: Reflections and Overview. http://hal-01069384. Acessado em: 01/11/2020.

Strawson, P. F. 1959. Individuals, An Essay in Descriptive Metaphysics. Londres: Routledge.

Strawson, P. F. 1963. Carnap's views on conceptual systems versus natural languages in analytic philosophy. In: P. A. Schilpp (ed.) The Philosophy of Rudolf Carnap, pp.503-18. Illinois: Open Court.

\section{Agradecimentos}

Esta resenha foi um resultado do curso do Programa de Pós-Graduação em Filosofia da UFMG Filosofia e Psicologia dos Conceitos (2020/1), ministrado pelo Professor André Abath em formato remoto emergencial. A ele agradeço pelo incentivo e comentários feitos à sua primeira versão, assim como às colegas de curso pelas discussões. Também agradeço a Mateus Leite pelas críticas e comentários e à/ao parecerista pelas observações. 